\title{
Clinical efficacy comparison of avapritinib with other tyrosine kinase inhibitors in gastrointestinal stromal tumors with PDGF $R A$ D842V mutation: a retrospective analysis of clinical trial and real-world data
}

\author{
Margaret von Mehren ${ }^{1 *}$ (D), Michael C. Heinrich ${ }^{2}$, Hongliang Shi ${ }^{3}$, Sergio lannazzo ${ }^{3}$, Raymond Mankoski ${ }^{3}$,
} Saša Dimitrijević ${ }^{3}$, Gerard Hoehn ${ }^{3}$, Silvia Chiroli ${ }^{3}$ and Suzanne George ${ }^{4}$

\begin{abstract}
Background: Avapritinib, a potent inhibitor of KIT and platelet-derived growth factor receptor A (PDGFRA) tyrosine kinases, has demonstrated unprecedented clinical activity in PDGFRA D842V-mutant gastrointestinal stromal tumors (GIST).

Methods: This retrospective analysis compared efficacy of avapritinib in patients enrolled in the NAVIGATOR phase 1 trial (NCT02508532) with the efficacy of other tyrosine kinase inhibitors (TKIs) in patients with unresectable/metastatic PDGFRA D842V-mutant GIST enrolled in a retrospective natural history study (Study 1002). The primary endpoint was overall survival (OS) from the start of reference treatment (avapritinib for NAVIGATOR patients or first-line TKI for treatment of unresectable/ metastatic GIST for Study 1002 patients); the secondary endpoint was progression-free survival (PFS). Adjusted Kaplan-Meier survival curves were compared by Cox regression.

Results: Fifty-six (NAVIGATOR) and 19 (Study 1002) patients with PDGFRA D842V-mutant GIST were evaluated; of the 56 patients from NAVIGATOR, a subgroup of patients treated with either $300 \mathrm{mg}$ (recommended phase 2 dose) or $400 \mathrm{mg}$ (maximum tolerated dose) avapritinib starting dose $(n=38)$ were analyzed separately. Patient characteristics were adjusted for imbalances by propensity score between the study groups. Inverse probability of treatment weighting-adjusted KaplanMeier analysis of OS showed median OS was not reached for NAVIGATOR patients treated with any of the avapritinib doses tested and was 12.6 months for Study 1002 patients; OS rate at 6/48 months was 100\%/63\% in NAVIGATOR and 56\%/17\% in Study $1002(P=0.0001)$. In the 300/400 mg subgroup, adjusted OS rates at $6 / 36$ months were $100 \% / 73$ and 68\%/20\% in Study 1002 ( $P=0.0016)$. Adjusted median PFS was 29.5 months in NAVIGATOR and 3.4 months in Study 1002.
\end{abstract}

Conclusions: In this indirect, retrospective analysis, avapritinib demonstrated more durable survival outcomes compared with other TKIs in patients with unresectable/metastatic PDGFRA D842V-mutant GIST.

Trial registration: The NAVIGATOR trial was registered at ClinicalTrials.gov as per July 2015, Identifier: NCT02508532.

Keywords: GIST, Avapritinib, PDGFRA D842V mutation

\footnotetext{
* Correspondence: Margaret.vonMehren@fccc.edu

'Department of Hematology/Oncology, Fox Chase Cancer Center, 333

Cottman Ave, Philadelphia, PA 19111, USA

Full list of author information is available at the end of the article
}

(c) The Author(s). 2021 Open Access This article is licensed under a Creative Commons Attribution 4.0 International License, which permits use, sharing, adaptation, distribution and reproduction in any medium or format, as long as you give appropriate credit to the original author(s) and the source, provide a link to the Creative Commons licence, and indicate if changes were made. The images or other third party material in this article are included in the article's Creative Commons licence, unless indicated otherwise in a credit line to the material. If material is not included in the article's Creative Commons licence and your intended use is not permitted by statutory regulation or exceeds the permitted use, you will need to obtain permission directly from the copyright holder. To view a copy of this licence, visit http://creativecommons.org/licenses/by/4.0/. The Creative Commons Public Domain Dedication waiver (http://creativecommons.org/publicdomain/zero/1.0/) applies to the data made available in this article, unless otherwise stated in a credit line to the data. 


\section{Background}

Over $85 \%$ of gastrointestinal stromal tumors (GIST) are driven by oncogenic mutations of the genes encoding KIT and/or platelet-derived growth factor receptor A (PDGFRA) receptor tyrosine kinases [1, 2]. The most common sites for mutations in GIST are in the juxtamembrane domain (exon 11; 60-70\%) and the extracellular domain (exon 9; 5-10\%) of KIT; mutations in PDGFRA (5-10\%) are most commonly located in the activation loop (exon 18) and the juxtamembrane domain (exon 12) [3-6].

Tyrosine kinase inhibitors (TKIs), developed to target pathogenic mutant kinases, have revolutionized the treatment landscape for patients with unresectable or metastatic GIST over the past two decades [7]. US and European treatment guidelines for GIST strongly recommend genetic testing for KIT and PDGFRA mutations, due to their response-predictive value and thus significance in guiding treatment decisions [8-10]. However, patients with unresectable/metastatic PDGFRA D842Vmutant GIST have a poor prognosis because imatinib and other approved TKIs lack activity against PDGFRA D842V-mutant kinases [3, 11, 12]. Approved treatments have provided, at best, very few objective responses in patients with the D842V mutation in clinical trials [13, 14]. For example, published studies have shown very infrequent responses with imatinib in PDGFRA D842V-mutant GIST, with only $3 \%$ (two out of 59 ) of patients across studies achieving a partial response to this treatment [3, 13-16]. To date, median progression-free survival (PFS) is between 2 and 10 months and median overall survival (OS) is approximately 9-25 months [13, 14, 17], thereby highlighting the urgent unmet medical need for patients with unresectable/metastatic GIST harboring the PDGFRA D842V mutation.

Avapritinib (formerly BLU-285, Blueprint Medicines Corporation, Cambridge, Massachusetts, USA) is a selective, potent inhibitor of KIT and PDGFRA mutant kinases, which is currently approved in the US for the treatment of adults with unresectable or metastatic GIST that harbor a PDGFRA exon 18 mutation, including D842V [18]. Avapritinib has also been approved in the EU for the treatment of adult patients with unresectable or metastatic GIST harboring the PDGFRA D842V mutation [19]. These approvals were based on the openlabel, non-randomized, phase 1 , dose escalation and dose expansion NAVIGATOR (ClinicalTrials.gov: NCT02508532) trial, designed to evaluate the safety and antineoplastic activity of avapritinib in patients with unresectable/ metastatic GIST, previously treated with TKIs. In this study, avapritinib showed unprecedented clinical efficacy and durable responses in patients with unresectable or metastatic PDGFRA D842V-mutant GIST. Study 1002 was a retrospective, observational, chart-based natural history study that evaluated the response and survival of patients with unresectable/metastatic PDGFRA D842Vmutant GIST treated during their clinical course with TKIs other than avapritinib [20]. The objective of this analysis was to retrospectively compare efficacy outcomes in patients treated with avapritinib in the NAVIGATOR trial with patients treated with other TKIs in Study 1002.

\section{Methods}

\section{Study design and patients}

Patients with unresectable/metastatic GIST harboring a PDGFRA D842V mutation were enrolled in NAVIGATOR, or retrospectively selected for Study 1002, based on their treatment history. For this analysis, the data cut-off for the NAVIGATOR trial was March 9, 2020. The detailed study design for NAVIGATOR was described previously [21]. Briefly, patients were enrolled in NAVIGATOR if they were $\geq 18$ years of age with a histologically- or cytologically-confirmed diagnosis of unresectable GIST that had progressed following imatinib and $\geq 1$ of the following: sunitinib, regorafenib, sorafenib, dasatinib, pazopanib or an experimental kinase-inhibitor agent, or had a disease with a D842V mutation in the PDGFRA gene. Mutational status was determined by local testing and centrally confirmed using circulating tumor DNA as well as archival or new tumor biopsy samples.

In Study 1002, which was conducted at three US sites, patients $\geq 18$ years of age with a confirmed diagnosis of GIST harboring a D842V mutation in PDGFRA were treated with a commercially available or investigational TKI. Patients were excluded from Study 1002 if they were enrolled in a clinical trial of avapritinib or if they had received prior TKI therapy only in an adjuvant setting. Demographic and clinical data from patients following each line of therapy were gathered retrospectively between January 2000 and July 2016.

\section{Study endpoints}

The primary endpoint of the current analysis was OS and the secondary endpoint was PFS, assessed in Study 1002 by Response Evaluation Criteria in Solid Tumors version 1.1 [22] and in NAVIGATOR by Response Evaluation Criteria in Solid Tumors version 1.1 with modifications for GIST as previously defined and used in a phase 3 trial of regorafenib [23]. OS and PFS were measured either from the start of treatment with avapritinib (in NAVIGATOR) or the first TKI prescribed for unresectable/metastatic GIST (in Study 1002), to the date of death event (OS and PFS) or disease progression (PFS).

\section{Statistical analysis}

The Kaplan-Meier method was used to obtain inverse probability of treatment weighting (IPTW)-adjusted and 
unadjusted survival curves for patients treated with avapritinib (NAVIGATOR) and other commercially available or investigational TKIs (Study 1002). IPTWadjusted Kaplan-Meier survival functions were estimated using calculated propensity score (PS) weighting, with the PS used to adjust for imbalances in the characteristics of patients included in NAVIGATOR and Study 1002. Calculated weights were generated using a PS multivariate logistic regression model that included age and presence of metastatic disease at the start of reference treatment, anatomical site of primary tumor at diagnosis, duration of disease from diagnosis to start of reference treatment, sex, and number of TKIs (counted from the first TKI for treatment of unresectable/metastatic GIST). Race and Eastern Cooperative Oncology Group (ECOG) performance status variables were not included due to a relatively high number of missing values. Each patient was assigned an individual weight based on the PS regression, with the weighted mean of the characteristics harmonized between the cohorts. With the IPTW method, patients in Study 1002 (control group) with a very high similarity to the baseline characteristics of the avapritinib treatment group (NAVIGATOR) are given relatively higher weights, whereas those with very high propensity scores will have lower weights. Log-rank and Cox regression-based tests were used to compare unadjusted and adjusted Kaplan-Meier survival curves, respectively, with the aim of testing the null hypothesis that there was no difference between survival curves for NAVIGATOR and Study 1002. All analyses were conducted using STATA software (Release 13; StataCorp, College Station, Texas, USA).

\section{Results}

Patients

A total of 56 patients in NAVIGATOR (all patients with PDGFRA D842V-mutant GIST) and 19 patients in Study 1002 were included in the analysis; of the 56 patients in NAVIGATOR, a subgroup of 38 patients who started avapritinib treatment at $300 \mathrm{mg}$ or $400 \mathrm{mg}$ was also analyzed separately (Fig. 1). In NAVIGATOR, the maximum tolerated dose was determined as $400 \mathrm{mg}$ and the recommended phase 2 dose was $300 \mathrm{mg}$ [21]. Although 22 patients were included in Study 1002 in total, three were excluded from the current analysis as the first TKI treatment for unresectable/metastatic GIST could not be identified (these patients only received imatinib in the adjuvant setting). Data were restricted to variables that were available in both studies at comparable time points (i.e., at the start of reference treatment).

Overall $(N=75 ; 56$ patients in NAVIGATOR and 19 patients in Study 1002), the majority of patients were male $(n=51 ; 68 \%)$, had GIST located in the stomach $(n=61 ; 81 \%)$, and over half the patients $(n=45 ; 60 \%)$ had unresectable/metastatic GIST for $<3$ years. Patient characteristics were balanced between the two studies for sex, race, tumor anatomical location, presence of metastatic disease, and duration of disease (Table 1). An analysis using the chi-square test showed that age was the only patient characteristic that was significantly different between the two cohorts $(P=0.046)$; in NAVI GATOR, 32\% (18/56) of patients were younger than 60 years, compared with 58\% (11/19) of patients in Study 1002. Overall, patients enrolled in NAVIGATOR received fewer previous lines of TKIs, with $61 \%(34 / 56)$ of

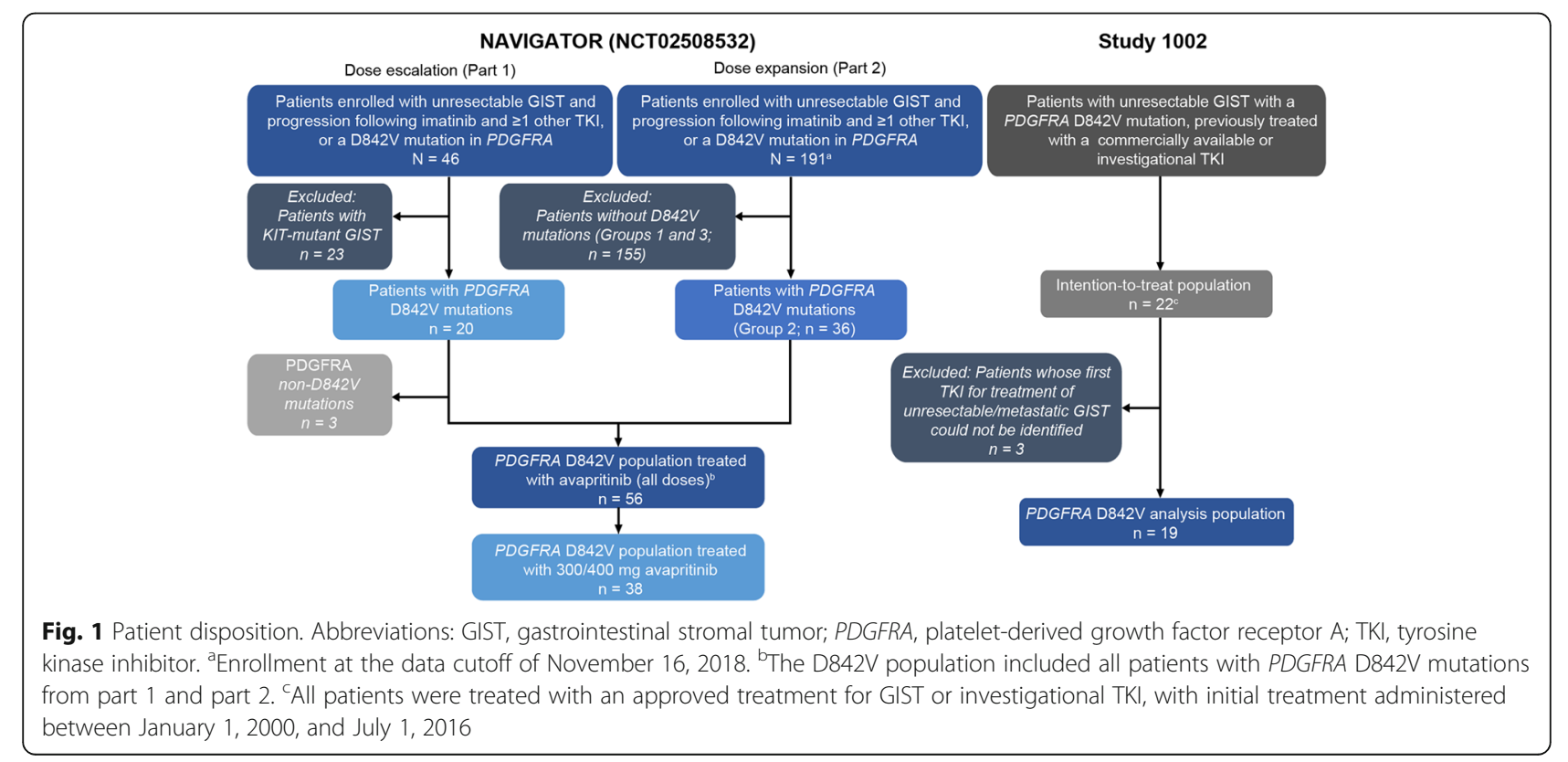


Table 1 Analysis of confounding patient-related factors

\begin{tabular}{|c|c|c|c|c|c|}
\hline \multirow{2}{*}{$\begin{array}{l}\text { Patient characteristic, } \\
\text { n (\%) }\end{array}$} & \multicolumn{2}{|c|}{ NAVIGATOR } & \multirow{2}{*}{$\begin{array}{l}\text { Study } \\
1002 \\
n=19\end{array}$} & \multicolumn{2}{|l|}{$P$ value } \\
\hline & $\begin{array}{l}\text { All doses } \\
n=56\end{array}$ & $\begin{array}{l}300 / 400 \mathrm{mg} \\
n=38\end{array}$ & & $\begin{array}{l}\text { NAVIGATOR } \\
\text { All doses vs } \\
\text { Study } 1002 \\
\end{array}$ & $\begin{array}{l}\text { NAVIGATOR } \\
300 / 400 \mathrm{mg} \\
\text { vs Study } 1002 \\
\end{array}$ \\
\hline$\overline{\text { Sex }}$ & & & & 0.601 & 0.844 \\
\hline Male & $39(70)$ & $25(66)$ & $12(63)$ & & \\
\hline Female & $17(30)$ & $13(34)$ & $7(37)$ & & \\
\hline $\mathrm{Age}^{\mathrm{a}}$ & & & & $0.046^{*}$ & 0.088 \\
\hline$<60$ years & $18(32)$ & $13(34)$ & $11(58)$ & & \\
\hline$\geq 60$ years & $38(68)$ & $25(66)$ & $8(42)$ & & \\
\hline Race & & & & 0.101 & $0.042^{*}$ \\
\hline White & $39(78)$ & $25(71)$ & $18(95)$ & & \\
\hline Non-white & $11(22)$ & $10(29)$ & $1(5)$ & & \\
\hline Missing & 6 & 3 & 0 & & \\
\hline Anatomical site ${ }^{b}$ & & & & 0.757 & 0.823 \\
\hline Gastric (stomach) & $46(82)$ & $29(76)$ & $15(79)$ & & \\
\hline $\begin{array}{l}\text { Small bowel or rectal } \\
\text { (any other organ) }\end{array}$ & $10(18)$ & $9(24)$ & $4(21)$ & & \\
\hline Metastatic disease $^{a}$ & & & & 0.745 & 0.611 \\
\hline No & $2(4)$ & $1(3)$ & $1(5)$ & & \\
\hline Yes & $54(96)$ & $37(97)$ & $18(95)$ & & \\
\hline ECOG Performance Status ${ }^{\mathrm{a}}$ & & & & 0.445 & 0.400 \\
\hline 0 & $21(38)$ & $13(34)$ & $1(100)$ & & \\
\hline 1 & $32(57)$ & $23(61)$ & 0 & & \\
\hline$\geq 2$ & $3(5)$ & $2(5)$ & 0 & & \\
\hline Missing & 0 & 0 & 18 & & \\
\hline Duration of disease $e^{c}$ & & & & 0.386 & 0.340 \\
\hline$<3$ years & $32(57)$ & $21(55)$ & $13(68)$ & & \\
\hline$\geq 3$ years & $24(43)$ & $17(45)$ & $6(32)$ & & \\
\hline Number of TKI treatment lines ${ }^{d}$ & & & & 0.124 & $0.040^{*}$ \\
\hline 1 & $11(20)$ & $5(13)$ & $3(16)$ & & \\
\hline 2 & $23(41)$ & $20(53)$ & $3(16)$ & & \\
\hline 3 & $9(16)$ & $6(16)$ & $4(21)$ & & \\
\hline$\geq 4$ & $13(23)$ & 7 (18) & $9(47)$ & & \\
\hline
\end{tabular}

Abbreviations: ECOG, Eastern Cooperative Oncology Group; TKI, tyrosine kinase inhibitor

Not all available baseline and demographic characteristics could be used due to differences in the timing of the measure (i.e., screening in NAVIGATOR vs diagnosis in Study 1002)

${ }^{\mathrm{a}}$ Estimated at the start of reference treatment

${ }^{\mathrm{b}}$ Recorded at the primary diagnosis

${ }^{c}$ Estimated from the date of diagnosis to the date of start of reference treatment

${ }^{d}$ The number of lines of TKIs was counted from the first TKI for treatment of unresectable/metastatic disease including avapritinib for NAVIGATOR population

${ }^{*} P$ value statistically significant $(\leq 0.05)$; comparison between NAVIGATOR population vs Study 1002 population

patients having received $\leq 2$ prior lines of TKIs compared with only $32 \%(6 / 19)$ in Study 1002; the highest proportion of patients had received two prior lines of TKIs (23/ 56; 41\%) in NAVIGATOR compared with $\geq 4$ prior lines of TKIs $(9 / 19 ; 47 \%)$ in Study 1002. Pre-avapritinib treatments received by patients in NAVIGATOR and treatments received by patients in Study 1002 are presented in
Supplementary Tables 1 and 2, respectively. In NAVIGATOR and Study 1002, the most commonly prescribed first- and second-line treatments were imatinib (NAVI GATOR: 36/42 [86\%]; Study 1002: 20/22 [91\%]) and sunitinib (NAVIGATOR: 14/24 [58\%]; Study 1002: 9/19 [47\%]), respectively. One patient received docetaxel/gemcitabine as a second-line treatment in Study 1002. There 
was no clear treatment preference among third- or fourthline agents. In NAVIGATOR, one patient received paclitaxel as a third-line treatment.

In the $300 / 400 \mathrm{mg}$ subgroup $(n=38)$, patient characteristics were also well balanced when compared with Study 1002. Chi-square tests showed patient race and the total number of prior lines of TKIs were the only significantly different factors $(P=0.042$ and $P=0.040$, respectively; Table 1 ). In the NAVIGATOR 300/400 mg subgroup, a lower proportion of patients were white (71\%; 25/35) compared with patients in Study 1002 (95\%; 18/19). In NAVIGATOR, similar to the overall population, patients in the $300 / 400 \mathrm{mg}$ subgroup received fewer previous lines of TKI therapy than patients in Study 1002.

\section{Overall survival}

Median OS was not reached in NAVIGATOR in both the adjusted and unadjusted analyses while in Study 1002, median OS was 12.6 months and 26.4 months, respectively. The Kaplan-Meier estimates for OS for NAVIGATOR (all patients) and the 300/400 mg subgroup compared with Study 1002 are presented in Fig. 2 (adjusted) and Fig. 3 (unadjusted), respectively. Adjusted and unadjusted OS rates were greater in the overall NAVIGATOR population (Figs. 2c and 3c) and in the 300/400 mg subgroup compared with Study 1002 (Figs. 2d and 3d) at all landmarks through to 24 and 36 months. In the adjusted analysis, OS rate at 48 months was $63 \%$ in the overall NAVIGATOR population compared with $17 \%$ for Study 1002 . In the $300 /$ $400 \mathrm{mg}$ subgroup, adjusted OS rate at 36 months was $73 \%$ compared with $20 \%$ in Study 1002.

Based on Cox regression analysis, the null hypothesis was rejected for the adjusted analysis for overall NAVI
GATOR population $(P=0.0001)$ and the $300 / 400 \mathrm{mg}$ subgroup $(P=0.0016)$, demonstrating that the difference between the survival curves, which favored avapritinib compared with other TKIs, was statistically significant.

\section{Progression-free survival}

Median PFS was 29.5 months in the adjusted and 29.2 months in the unadjusted analysis in NAVIGATOR compared with 3.4 months in Study 1002 (both adjusted and unadjusted). For PFS, the Kaplan-Meier estimates are shown in Fig. 4 (adjusted) and Fig. 5 (unadjusted). Adjusted and unadjusted PFS rates were greater in the overall NAVIGATOR population (Figs. $4 \mathrm{c}$ and $5 \mathrm{c}$ ) and in the 300/400 mg subgroup compared with Study 1002 (Figs. 4d and 5d) at all landmarks through 12 and 24 months. In the adjusted analysis, PFS rate at 24 months was $63 \%$ in the overall NAVIGATOR population compared with $6 \%$ for Study 1002. In the $300 / 400 \mathrm{mg}$ subgroup, adjusted PFS rate at 24 months was $54 \%$ compared with $5 \%$ in Study 1002. In both cohorts of NAVIGATOR (all patients and 300/400 mg subgroup), the null hypothesis was rejected for this analysis as the test was significant $(P<0.00001)$.

\section{Discussion}

This is the first retrospective statistical analysis conducted to evaluate treatment outcomes with avapritinib compared with other TKIs in patients with unresectable/metastatic PDGFRA D842V-mutant GIST. Data in this patient population are currently limited due to the low prevalence of GIST associated with PDGFRA D842V mutations. Additionally, very limited data are available on the outcome of treatment with TKIs in these patients.
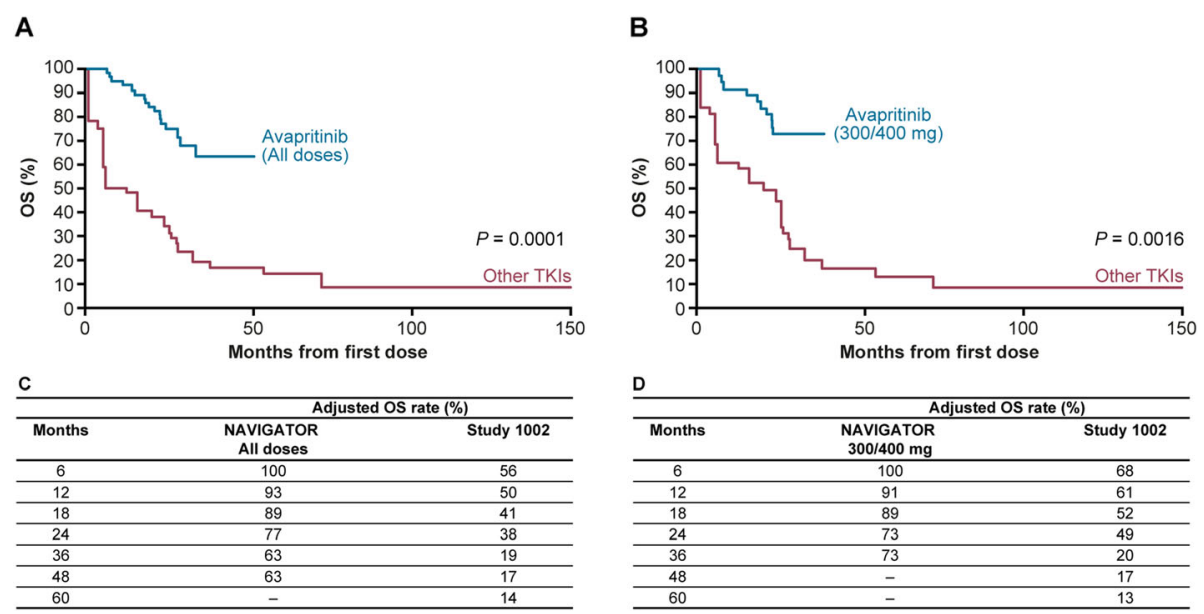

Fig. 2 Adjusted Kaplan-Meier overall survival estimates. a Overall NAVIGATOR population vs Study 1002. b NAVIGATOR $300 / 400$ mg subgroup vs Study 1002. c Adjusted OS landmark analyses for NAVIGATOR population and Study 1002. d Adjusted OS landmark analyses for NAVIGATOR 300/ $400 \mathrm{mg}$ subgroup and Study 1002 
A

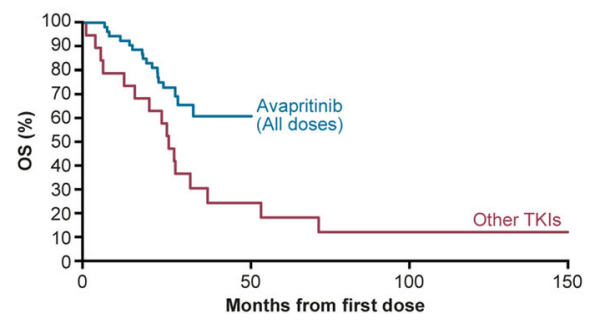

$\underline{\mathrm{c}}$

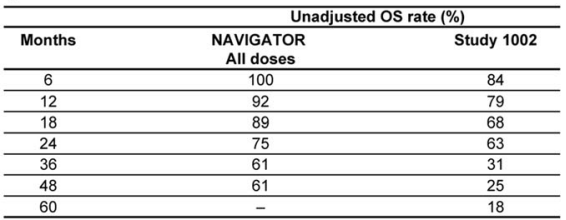

B
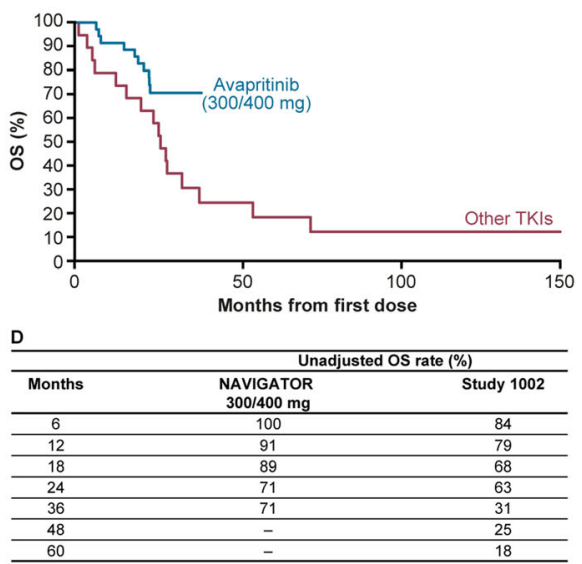

Fig. 3 Unadjusted Kaplan-Meier overall survival estimates. a Overall NAVIGATOR population vs Study 1002. b NAVIGATOR $300 / 400$ mg subgroup vs Study 1002. c Undjusted OS landmark analyses for NAVIGATOR population and Study 1002. d Unadjusted OS landmark analyses for NAVI GATOR 300/400 mg subgroup and Study 1002

In the most recently published NAVIGATOR trial results, avapritinib demonstrated significant clinical activity and durable responses in patients with unresectable/ metastatic PDGFRA D842V-mutant GIST. In patients treated with $300 / 400 \mathrm{mg}$, the centrally confirmed overall response was 95\% (36/38 patients, 95\% confidence interval [CI] 82-99) with 5 (13\%) complete responses and 31 (82\%) partial responses. Median duration of response was 22 months (95\% CI 14-not reached) and median PFS was 24 months (95\% CI 18-not reached); median OS was not reached at a median follow-up of 27.5 months, with an estimated OS rate of $71 \%$ at 36 months [24]. In the analysis reported here, statistical adjustments were made to control for confounding factors in order to determine the primary and secondary outcomes.
IPTW-adjusted OS and PFS analysis was chosen over more conventional matching methods for several reasons: first, unlike other matching methods study patients are rarely eliminated from the analysis, which is suitable for studies which have a limited sample size and allowed retention of the highest possible number of observations in the analysis; second, IPTW serves to reduce or remove the effects of confounding factors in nonrandomized studies; finally, the application of the IPTW method has also been reported in two similar recently published analyses (these consisted of single-arm studies of ceritinib and blinatumomab compared with historical control groups). Findings from both these trials supported regulatory approvals $[25,26]$. In Study 1002, the median adjusted and unadjusted OS differed (12.6
A

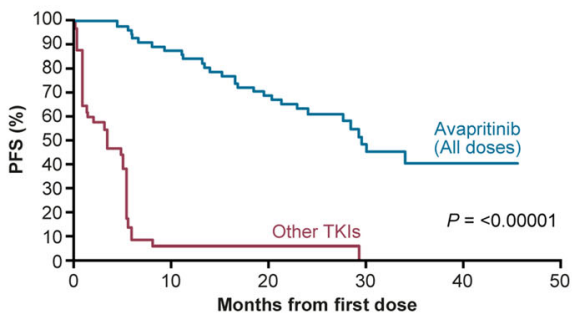

c

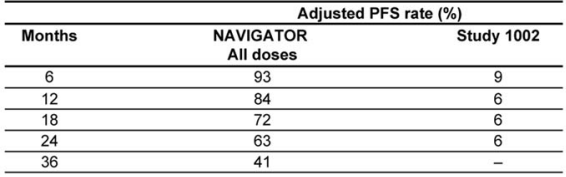

B

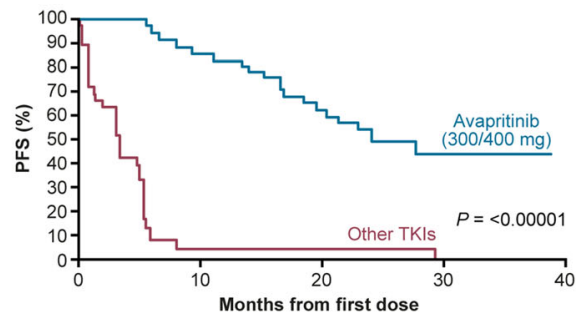

$\underline{\underline{D}}$

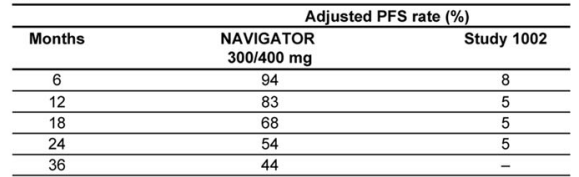

Fig. 4 Adjusted Kaplan-Meier progression-free survival estimates. a Overall NAVIGATOR population vs Study 1002. b NAVIGATOR 300/400 mg subgroup vs Study 1002. c Adjusted PFS landmark analyses for NAVIGATOR population and Study 1002. d Adjusted PFS analyses for NAVIGATOR 300/400 mg subgroup and Study 1002 
A

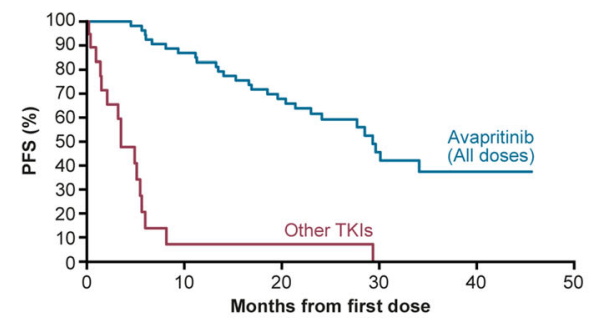

c

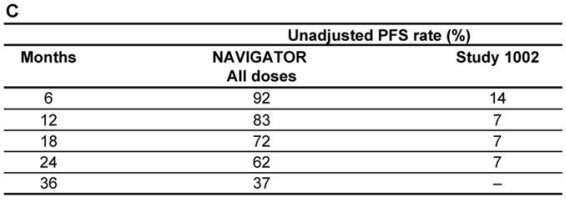

B

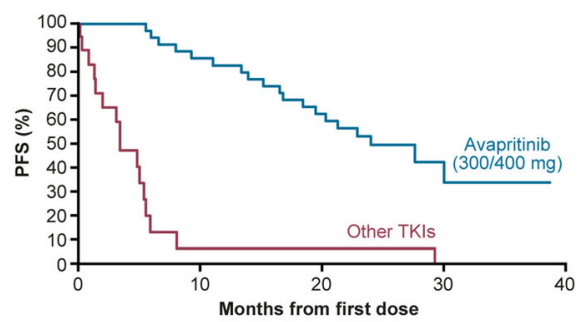

$\underline{D}$

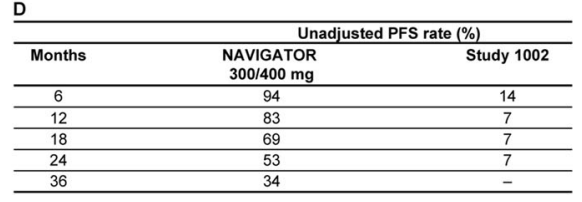

Fig. 5 Unadjusted Kaplan-Meier progression-free survival estimates. a Overall NAVIGATOR population vs Study 1002. b NAVIGATOR 300/400 mg subgroup vs Study 1002. c Unadjusted PFS landmark analyses for NAVIGATOR population and Study 1002. d Unadjusted PFS analyses for NAVI GATOR 300/400 mg subgroup and Study 1002

months and 26.4 months respectively), whereas the median PFS adjusted and unadjusted values were the same (3.4 months). The greater impact of adjustment on OS compared with PFS may be due to the greater range and variability of OS values. In addition, the smaller number of death events compared with progression events may also be an explanation.

Our indirect analysis has a number of limitations. In Study 1002, OS was measured from the start of the first TKI used for unresectable/metastatic GIST, but in the NAVIGATOR trial, OS was measured from the start of avapritinib treatment. Therefore, the impact of previous TKI therapies on the survival benefits of avapritinib cannot be extrapolated from these results, although all patients included in this study had PDGFRA D842Vmediated resistance to currently approved TKI-based therapies. It is important to note that avapritinib is currently approved for unresectable/metastatic PDGFRA D842V-mutant GIST, regardless of the line of therapy $[18,19]$. In real-world clinical practice, avapritinib is expected to be used as a first-line TKI for this indication, hence, it will be crucial to collect and publish data evaluating avapritinib in the first-line setting for unresectable/ metastatic PDGFRA D842V-mutant GIST. In addition, although patient characteristics were generally well balanced between the two studies, age (overall NAVIGATOR population), race, and the total number of prior lines of TKI therapy (NAVIGATOR 300/400 mg subgroup) were significantly different compared with patients in Study 1002. The higher number of prior TKI treatments received by patients in Study 1002 patients reflects the use of available TKIs with the characteristic treatment resistance to PDGFRA D842V mutations before the approval of avapritinib for PDGFRA exon 18 and D842V-mutant GIST. Furthermore, analyses of retrospective studies such as Study 1002 risk overestimation of PFS duration. However, despite this risk, we still observed significant differences in PFS between NAVI GATOR and Study 1002. Comparisons between PFS may also have been impacted by differences in evaluation criteria between NAVIGATOR and Study 1002; OS comparisons were not affected by differences in assessment criteria. It should also be noted that $P$ values should be interpreted with caution as this is an indirect analysis. Lastly, as a retrospective study, adverse event data were not collected for Study 1002, so safety comparisons with NAVIGATOR could not be conducted. A comprehensive post-hoc analysis of the safety and tolerability of avapritinib in the dose escalation/expansion phase I NAVIGATOR study, including guidance on management of cognitive effects and intracranial bleeding events, has been presented previously [27].

\section{Conclusions}

This retrospective, indirect analysis suggests avapritinib leads to more durable survival outcomes in patients with PDGFRA D842V-mutant unresectable/metastatic GIST than other TKIs used for treating patients with GIST. In addition, Study 1002 confirmed that the prognosis of patients in this population treated with TKIs available prior to avapritinib approval was poor. Overall, these results underscore the importance of tumor mutational testing at initial diagnosis, to ensure the most effective and clinically appropriate treatment is provided.

\section{Abbreviations}

GIST: Gastrointestinal stromal tumors; PDGFRA: Platelet-derived growth factor receptor $A_{\text {; }}$ TKIs: Tyrosine kinase inhibitors; PFS: Progression-free survival; OS: Overall survival; iPTW: Inverse probability of treatment weighting; PS: Propensity score; ECOG: Eastern Cooperative Oncology Group 


\section{Supplementary Information}

The online version contains supplementary material available at https://doi. org/10.1186/s12885-021-08013-1

Additional file 1: Supplementary Table 1. Prior treatments received by patients in NAVIGATOR. Supplementary Table 2. Prior treatments received by patients in Study 1002. Supplementary Table 3. NAVI GATOR study investigational sites and institutional review boards (IRB) or independent ethics committees (EC) list. Supplementary Table 4. Study 1002 investigational sites and institutional review boards (IRB) list.

\section{Acknowledgments}

The authors would like to thank the patients, their families and all investigators involved in this study as well as Tucker Berk from Dana-Farber Cancer Institute and Brittany Peterson from the Fox Chase Cancer Center, for the data abstraction and data collection of patients. Medical writing support was provided by Manoshi Nath, MSc, and editorial support was provided by Michelle Seddon, Dip Psych, and Travis Taylor of Paragon, Knutsford, UK, and was supported by Blueprint Medicines Corporation, Cambridge, Massachusetts, USA, according to Good Publication Practice guidelines.

\section{Authors' contributions}

MvM, MH, HS, SI, SD, SG were responsible for the study concept and design, data acquisition, and data analysis. All authors - MvM, MH, HS, SI, RM, SD, GH, SC, SG - were involved in data interpretation and writing, revising, and approving the final manuscript. All authors have also agreed to be both personally accountable for the author's own contributions and to ensure that questions related to the accuracy or integrity of any part of the work, even ones in which the author was not personally involved, are appropriately investigated, resolved, and the resolution documented in the literature.

\section{Funding}

The study was designed by the funder (Blueprint Medicines Corporation) in collaboration with the investigators. The funder collected, analyzed, and interpreted the data in conjunction with the authors, who had access to all data.

\section{Availability of data and materials}

The anonymized derived data from NAVIGATOR and Study 1002 that underlie the results reported in this article will be made available, beginning 12 months and ending 5 years following this article's publication, to any investigators who sign a data access agreement and provide a methodologically sound proposal to medinfo@blueprintmedicines.com. The trial protocol will also be made available, as will a data fields dictionary.

\section{Declarations}

\section{Ethics approval and consent to participate}

The protocol of the NAVIGATOR trial was approved by the institutional review board or independent ethics committee of each study center. The study was conducted in accordance with the International Conference on Harmonisation/Good Clinical Practice Guidelines, the ethical principles of the Declaration of Helsinki, and applicable national and local regulatory requirements. All patients provided written informed consent. Study 1002 was conducted at sites that granted institutional review board approval and in full compliance with the principles of the Declaration of Helsinki. Due to the retrospective nature of the study, ethical considerations were limited to patient confidentiality and privacy. A list of NAVIGATOR and Study 1002 institutional review boards or independent ethics committees of each study site is provided in supplementary Tables 3 and 4, respectively. Since PDGFRA-driven GIST is rare, de-identification of data may not have provided full protection of patient confidentiality. Therefore, a limited data set approach was used to allow disclosure of protected health information as defined by the Health Insurance Portability and Accountability Act for research purposes. Individual patient consent was not obtained due to the non-interventional and retrospective nature of the study.

\section{Consent for publication}

The manuscript does not contain data from any individual person, and so consent for publication is not applicable for inclusion in this report.

\section{Competing interests}

Dr. von Mehren reported receiving other support from Arog Pharmaceuticals and Deciphera Pharmaceuticals outside the submitted work and other support from Blueprint Medicines Corporation during the conduct of the study. Dr. von Mehren and Dr. Heinrich both report funding from GIST Cancer Research Fund and the Jonathan David Foundation. Dr. Heinrich reports grants and personal fees from Blueprint Medicines Corporation, and a US Veterans Administration Merit Review Grant (I01 BX000338, MCH) during the conduct of the study, grants and personal fees from Deciphera Pharmaceuticals, outside the submitted work, other from MolecularMD, during the conduct of the study and personal fees and other from Novartis; in addition, Dr. Heinrich has a patent "Treatment of Gastrointestinal Stromal Tumors" licensed to Novartis, and having a patent "Activating Mutations of PDGFRA" issued. At the time of development of this study, Sergio lannazzo was employed by Hetegy, a health economics consulting company which received consulting fees from Blueprint Medicines Corporation. Sergio lannazzo is currently an employee and shareholder of Blueprint Medicines Corporation. Dr. George reports personal fees from Bayer, Blueprint Medicines Corporation, Daiichi Sankyo, Deciphera Pharmaceuticals, Eli Lilly, Exelixis, MORE Health, Research to Practice and UpToDate, and grants from ARIAD, Bayer, Blueprint Medicines Corporation, Deciphera Pharmaceuticals, Novartis, Pfizer, outside the submitted work; stock in Abbott Laboratories and Allergan; expert testimony for Bayer; relationship with Research to Practice; and royalties from UpToDate. Hongliang Shi, Raymond Mankoski, Saša Dimitrijević, Gerard Hoehn and Silvia Chiroli are employees and shareholders of Blueprint Medicines Corporation.

\section{Author details}

${ }^{1}$ Department of Hematology/Oncology, Fox Chase Cancer Center, 333 Cottman Ave, Philadelphia, PA 19111, USA. ²Division of Hematology and Medical Oncology, Portland VA Health Care System and Oregon Health \& Science University, Knight Cancer Institute, Portland, OR, USA. ${ }^{3}$ Blueprint Medicines Corporation, Cambridge, MA, USA. ${ }^{4}$ Dana-Farber Cancer Institute and Harvard Medical School, Boston, MA, USA.

Received: 9 October 2020 Accepted: 4 March 2021

Published online: 19 March 2021

\section{References}

1. Heinrich MC, Maki RG, Corless CL, Antonescu CR, Harlow A, Griffith D, Town A, McKinley A, Ou WB, Fletcher JA, et al. Primary and secondary kinase genotypes correlate with the biological and clinical activity of sunitinib in imatinib-resistant gastrointestinal stromal tumor. J Clin Oncol. 2008;26(33): 5352-9.

2. Heinrich MC, Corless CL, Duensing A, McGreevey L, Chen C-J, Joseph N, Singer S, Griffith DJ, Haley A, Town A, et al. PDGFRA activating mutations in gastrointestinal stromal tumors. Science. 2003;299(5607):708-10.

3. Heinrich MC, Corless CL, Demetri GD, Blanke CD, von Mehren M, Joensuu $H$, McGreevey LS, Chen C-J, Van den Abbeele AD, Druker BJ, et al. Kinase mutations and imatinib response in patients with metastatic gastrointestinal stromal tumor. J Clin Oncol. 2003;21(23):4342-9.

4. Smrke A, Gennatas S, Huang P, Jones RL. Avapritinib in the treatment of PDGFRA exon 18 mutated gastrointestinal stromal tumors. Future Oncol. 2020;16:1639-46 [Epub ahead of print].

5. Oppelt PJ, Hirbe AC, Van Tine BA. Gastrointestinal stromal tumors (GISTs): point mutations matter in management, a review. J Gastrointest Oncol. 2017;8(3):466-73.

6. Yim E, An HJ, Cho U, Kim Y, Kim SH, Choi Y-G, Shim BY. Two different KIT mutations may lead to different responses to imatinib in metastatic gastrointestinal stromal tumor. Korean J Intern Med. 2018;33(2):432-4.

7. Li K, Cheng H, Li Z, Pang Y, Jia X, Xie F, Hu G, Cai Q, Wang Y. Genetic progression in gastrointestinal stromal tumors: mechanisms and molecular interventions. Oncotarget. 2017;8(36):60589-604.

8. National Comprehensive Cancer Network. NCCN Clinical Practice Guidelines in Oncology: Soft tissue sarcoma (version 6) 2019. Available from: https://www.nccn.org/professionals/physician gls/pdf/sarcoma.pdf [Accessed 5 Mar 2020]. 
9. Casali PG, Abecassis N, Aro HT, Bauer S, Biagini R, Bielack S, Bonvalot S, Boukovinas I, Bovee JV, Brodowicz T, et al. Gastrointestinal stromal tumours: ESMO-EURACAN Clinical Practice Guidelines for diagnosis, treatment and follow-up. Ann Oncol. 2018;29(Suppl 4):iv68-78.

10. Wozniak A, Rutkowski P, Piskorz A, Ciwoniuk M, Osuch C, Bylina E, Sygut J, Chosia M, Rys J, Urbanczyk K, et al. Prognostic value of KIT/PDGFRA mutations in gastrointestinal stromal tumours (GIST): polish clinical GIST registry experience. Ann Oncol. 2012;23(2):353-60.

11. Roubaud G, Kind M, Coindre JM, Maki RG, Bui B, Italiano A. Clinical activity of sorafenib in patients with advanced gastrointestinal stromal tumor bearing PDGFRA exon 18 mutation: a case series. Ann Oncol. 2012;23(3):804-5.

12. Hirota S, Ohashi A, Nishida T, Isozaki K, Kinoshita K, Shinomura Y, Kitamura Y. Gain-of-function mutations of platelet-derived growth factor receptor alpha gene in gastrointestinal stromal tumors. Gastroenterology. 2003;125(3):660-7.

13. Cassier PA, Fumagalli E, Rutkowski P, Schoffski P, Van Glabbeke M, DebiecRychter M, Emile JF, Duffaud F, Martin-Broto J, Landi B, et al. Outcome of patients with platelet-derived growth factor receptor alpha-mutated gastrointestinal stromal tumors in the tyrosine kinase inhibitor era. Clin Cancer Res. 2012;18(16):4458-64.

14. Yoo C, Ryu MH, Jo J, Park I, Ryoo BY, Kang YK. Efficacy of imatinib in patients with platelet-derived growth factor receptor alpha-mutated gastrointestinal stromal tumors. Cancer Res Treat. 2016;48(2):546-52.

15. Farag $S$, Somaiah $N$, Choi $H$, Heeres $B$, Wang WL, van Boven $H$, Nederlof $P$, Benjamin R, van der Graaf W, Grunhagen D, et al. Clinical characteristics and treatment outcome in a large multicentre observational cohort of PDGFRA exon 18 mutated gastrointestinal stromal tumour patients. Eur J Cancer. 2017:76:76-83

16. Debiec-Rychter $M$, Sciot $R$, Le Cesne A, Schlemmer $M$, Hohenberger $P$, van Oosterom AT, Blay JY, Leyvraz S, Stul M, Casali PG, et al. KIT mutations and dose selection for imatinib in patients with advanced gastrointestinal stromal tumours. Eur J Cancer. 2006:42(8):1093-103.

17. Rutkowski P, Bylina E, Klimczak A, Switaj T, Falkowski S, Kroc J, Lugowska I, Brzeskwiniewicz M, Melerowicz W, Osuch C, et al. The outcome and predictive factors of sunitinib therapy in advanced gastrointestinal stromal tumors (GIST) after imatinib failure - one institution study. BMC Cancer. 2012;12:107

18. Blueprint Medicines Corporation. AYVAKIT (avapritinib). Prescribing information. 2020. Available from: https://www.accessdata.fda.gov/drugsa tfda_docs/label/2020/212608s000lbl.pdf [Accessed 28 July 2020].

19. Blueprint Medicines Corporation. AYVAKYT (avapritinib). Summary of product characteristics. 2020. Available from: https://www.ema.europa.eu/ en/documents/product-information/ayvakyt-epar-product-information_en. pdf [Accessed 4 Oct 2020]

20. von Mehren M, Heinrich MC, Shi H, McNamara P, Mamlouk KK, Boral A, George S. A retrospective natural history study of patients (pts) with PDGFRa D842V mutant advanced gastrointestinal stromal tumor (GIST) previously treated with a tyrosine kinase inhibitor (TKI). J Clin Oncol. 2018;36(15 suppl):11533.

21. Heinrich MC, Jones RL, von Mehren M, Schöffski P, Serrano C, Kang YK, Cassier PA, Mir O, Eskens F, Tap WD, et al. Avapritinib in advanced PDGFRA D842V-mutant gastrointestinal stromal tumour (NAVIGATOR): a multicentre, open-label, phase 1 trial. Lancet Oncol. 2020;21(7):935-46.

22. Eisenhauer EA, Therasse P, Bogaerts J, Schwartz LH, Sargent D, Ford R, Dancey J, Arbuck S, Gwyther S, Mooney M, et al. New response evaluation criteria in solid tumours: revised RECIST guideline (version 1.1). Eur J Cancer. 2009;45(2):228-47.

23. Demetri GD, Reichardt P, Kang Y-K, Blay J-Y, Rutkowski P, Gelderblom H, Hohenberger $P$, Leahy $M$, von Mehren $M$, Joensuu $H$, et al. Efficacy and safety of regorafenib for advanced gastrointestinal stromal tumours after failure of imatinib and sunitinib (GRID): An international, multicentre, randomised, placebo-controlled, phase 3 trial. Lancet. 2013;381(9863):295-302.

24. Jones RL, Serrano C, von Mehren M, George S, Heinrich M, Kang Y, Schoeffski P, Cassier P, Mir O, Chawla SP, Eskens FA, et al. Long-term efficacy, tolerability and overall survival in patients (pts) with unresectable or metastatic (U/M) PDGFRA D842V-mutant gastrointestinal stromal tumour (GIST) treated with avapritinib: NAVIGATOR phase I trial update. Ann Oncol. 2020;31(4):S914-33.

25. Davies J, Martinec M, Delmar P, Coudert M, Bordogna W, Golding S, Martina $R$, Crane G. Comparative effectiveness from a single-arm trial and real-world data: alectinib versus ceritinib. J Comp Eff Res. 2018;7(9):855-65.
26. Gökbuget N, Kelsh M, Chia V, Advani A, Bassan R, Dombret H, Doubek M, Fielding AK, Giebel S, Haddad V, et al. Blinatumomab vs historical standard therapy of adult relapsed/refractory acute lymphoblastic leukemia. Blood Cancer J. 2016:6(9):e473.

27. Joseph CP, Abaricia SN, Angelis MA, Polson K, Jones RL, Kang YK, Riedel R, Schoffski P, Serrano C, Trent J, et al. Optimal avapritinib treatment strategies for patients with metastatic or unresectable gastrointestinal stromal tumors. Oncologist. 2021;25:1-10.

\section{Publisher's Note}

Springer Nature remains neutral with regard to jurisdictional claims in published maps and institutional affiliations.
Ready to submit your research? Choose BMC and benefit from:

- fast, convenient online submission

- thorough peer review by experienced researchers in your field

- rapid publication on acceptance

- support for research data, including large and complex data types

- gold Open Access which fosters wider collaboration and increased citations

- maximum visibility for your research: over $100 \mathrm{M}$ website views per year

At BMC, research is always in progress.

Learn more biomedcentral.com/submissions 